\title{
Representaciones del cuerpo infantil en los libros de texto mexicanos, 1880-1940
}

Resumen: El objetivo de este trabajo es observar las representaciones y los discursos sobre el cuerpo infantil en la escuela primaria mexicana. Para este trabajo se tomaran como ejes principales el análisis de la imagen y del texto, de los libros que circularon dentro de la escuela primaria mexicana entre 1882 y 1940. Textos que circularon, en un primer momento, en todo el País, como producto de los acuerdos tomados en los tres congresos higiénicos y de instrucción pública $(1882,1889$ y 1890) y que se renovaran paulatinamente con la imposición de otros proyectos educativos. Si en una primera etapa los escritores atendieron a un lector urbano, donde las historias del niño rural, indígena o pobre se convirtieron en ejemplos de los males de la sociedad que debían ser corregidos por el régimen de la modernidad y de la ciencia para transformarlos en ciudadanos productivos, este esquema se revertirá en la segunda década del siglo XX, con el fin de educar a la masa infantil que vivía en el campo.

Palabras-clave: cuerpo; cultura infantile; libros de texto.

Representations of children's bodies in the Mexican textbooks, I880-1940

Abstract: The aim of this study is to analyze the representations and speeches on the children's body in Mexican primary school, and to see how hygiene, morality and gender relations are conceived. Its main source is a set of books, from different disciplines, that circulated between 1882 and 1940. They were published as a result of agreements reached in three hygienic and educational congresses $(1882,1889$ and 1890) and were updated in response to other educational projects such as the Rural School (1920) and the Socialist School (1940). In a first stage, the writer addresses the urban reader, where stories of rural children, indigenous or poor, became an example of the evils of society that could only be overcome by modernity and science, giving birth to productive citizens. During the second decade of the twentieth century, educational speech privileges the children living in the countryside, those who will shape the future working class. Books in general sought to interest the children in the reading of useful questions, with topics based on the virtues of manual labor and environmental care to meet the needs of civilization.

Key words: body; children's culture; books.

Profesora investigadora del Instituto de Ciencias de la Educación de la Universidad Autónoma del Estado de Morelos, Mexico. luciamoctezuma@yahoo.com.mx 
El objetivo de este trabajo es analizar las representaciones sobre el cuerpo infantil en la escuela primaria mexicana. El cuerpo como objeto cultural, como producto de la construcción de una sociedad y de un grupo social determinado cuya representación se transforma según el contexto histórico y social, en el que el Estado se esfuerza por controlarlo, en este caso, atendiendo a los discursos de los autores de libros de texto, maestros en su mayoría, pero también doctores, pedagogos y miembros de la administración escolar, quienes serán los responsables de construir un conocimiento sobre el niño dentro del contexto positivista y liberal de la época. Cuerpos infantiles regulados y protegidos por las normas impuestas en el espacio escolar a través de los discursos que se transmiten en las lecciones que se dictan en clase y que los cuadriculan, para someterlos a normas estrictas ${ }^{1}$ (Roy, 1993:275).

Escrituras que muestran una representación del cuerpo infantil asociada a sus rasgos biológicos, a su capacidad mental o psicológica y que se condensan en libros que circulan en la escuela. Manuales que en los últimos tiempos se han vuelto una valiosa fuente de información para los estudiosos de la historia de la educación porque el libro, es más que una asociación material, tangible, reconocible y específica, con distintos formatos que encierran textos ${ }^{2}$; es una práctica cultural y social vinculada estrechamente con los lectores y las condiciones sociales de su tiempo. Su riqueza ha hecho que en los últimos años se haya multiplicado el interés por el estudio de los modos y maneras de leer cuyo estudio se ha traducido en temas como el aprendizaje de la lectura, el análisis de los objetos e instrumentos utilizados en la escuela, sus motivaciones y las representaciones e imágenes mentales de la lectura (Martínez Martín Jesús A. 2005:11- 12).

Atravesado por un conjunto de saberes que forman el currículo escolar, el cuerpo infantil sirve de observatorio para mirar cómo se concibe la higiene, la

I. "Las pedagogías son portadoras de preceptos que dan al cuerpo una forma y lo cuadriculan para someterlo a normas con mayor seguridad aún de lo que haría el pensamiento. Se trata de imágenes sugeridas, de gestos esbozados que silenciosamente inducen posiciones y comportamientos, de frases anodinas, donde las palabras, sin parecerlo, dibujan un comportamiento semiconsciente y al mismo tiempo laborioso, de frases más gravitantes, portadoras de órdenes impartidas que fijan con precisión analítica o solemne el aspecto y los modales. El cuerpo es el primer lugar donde la mano del adulto marca al niño, es el primer espacio sonde se imponen los límites sociales y psicológicos que le dan a su conducta, es el emblema donde la cultura inscribe sus signos como si fueran blasones" (Vigarello, 200 I:9).

2. "Los libros escolares constituyen la condensación en un objeto de numerosos intereses, intenciones, intervenciones y regulaciones. Son la resultante del trabajo y la participación del autor, del editor, del diseñador, de la imprenta, del distribuidor, del maestro, de las autoridades educativas, etc y constituyen un fenómeno pedagógico pero también cultural, político, administrativo, técnico y económico. En los países latinoamericanos la evolución y las características de los libros escolares estarán íntimamente asociadas... a las transformaciones sociopolíticas y técnicas más o menos universales...y a la extensión de la alfabetización, a las concepciones pedagógicas y al desarrollo del sistema educativo...."(Ossenbach y Somoza , 200 I : I 5)

Pro-Posições, Campinas, v. 22, n. 3 (66), p. 35-49, set./dez. 2011 
moral y las relaciones de género. Todas las disciplinas escolares imponen una serie de actitudes que, a través de rituales, se realizan en la práctica. El lector adopta una actitud determinada dentro de la clase al ponerse de pie, tomar el libro o el lápiz, modular la voz durante la lectura en voz alta, recargar la espalda en forma recta en el pupitre al comenzar a escribir; un esquema que se repite también en el aprendizaje del canto, la gimnasia, los ejercicios militares y la economía doméstica donde el cuerpo adopta formas propias del género. Para este trabajo se toma como eje principal, el análisis de libros que circularon dentro de la escuela primaria mexicana entre 1882 y $1940^{3}$. Textos que se publicaron como producto de los acuerdos tomados en los tres congresos higiénicos y pedagógicos (1882, 1889 y 1890) de finales del siglo XIX, y que se modificaron paulatinamente con la propuesta de otros proyectos educativos vigentes entre 1920 y 1940 (La Escuela Rural y la Escuela Socialista).

En un primer momento, los escritores adoptaron un modelo que atendía al medio urbano, donde las historias del niño rural, indígena o pobre se convirtieron en ejemplo de los males de la sociedad que debían ser corregidos por la modernidad y la ciencia para ser transformados en ciudadanos productivos. Libros que fueron editados y adaptados por editoriales extranjeras a finales del siglo XIX y que se renovaron hacia 1921, cuando se crea la Secretaría de Educación Pública implementando nuevos proyectos que buscaban educar a la población infantil que vivía en el campo. Las políticas públicas destinadas a la infancia se centraron entonces en la higienización de la comunidad estableciendo una serie de estrategias para evitar enfermedades, comer sanamente, desarrollar habilidades para el trabajo, liberarlos del fanatismo y en la medida de lo posible, controlar desde la escuela sus hábitos, sus formas de expresión, sus modales y patrones de consumo. Los libros de texto, en general, sirvieron para interesar al niño en la lectura de cuestiones útiles, con temas basados en las virtudes del trabajo manual, que les ayudara a enfrentar la competencia y las necesidades impuestas por la civilización, para dedicarse a un oficio (Trigo, 1895 :15-17; Marcoin Francis, 1997: 23) ${ }^{4}$.

3. En un interesante balance sobre el tema se planteaba que aún había vetas por explorar para el caso de Iberoamérica. Una de ellas era la interpretación de los distintos lenguajes en los textos: el lenguaje manifiesto y el currículo oculto; el lenguaje de la palabra y el de la imagen (Ossenbach y Somoza, 2001:33).

4. A diferencia de los libros de cuentos, la lectura de la imagen en los libros de texto es relevante porque olvida su papel de dama de compañía o de criada, para rescatar su finalidad. La imagen tiene una función didáctica: deja su papel descriptivo y responde a las necesidades del aprendizaje cognitivo, “. . . la relación de fuerza existente entre figuras analógicas (imagen) fáciles de identificar, y signos arbitrarios (texto) difíciles de descifrar, amenaza el orden del texto impreso.... texto e imagen quedan dispuestos cara a cara, obligando a una lectura simultánea en el que la imagen deja su rol ornamental (Parmegiani Claude-Anne, 1997:56).

Pro-Posiçôes, Campinas, v. 22, n. 3 (66), p. 35-49, set./dez. 2011 
En los primeros años, los textos abogan por un mundo cosmopolita, urbano y francés mientras que en los siguientes, se representa a un mundo amable, respetuoso de la naturaleza donde los hombres mantienen la tierra sin abusarla y la pobreza casi no existe pues se asocia la lectura con la alegría y la cordialidad entre grupos (Marcoin Francis, 1997: 27)

\section{Los libros de texto en México: higiene, moral y género}

En su informe de 1875, el Ministro de Justicia e Instrucción Pública, José Díaz Covarrubias, hacía hincapié que la enseñanza en las escuelas primarias sufría un gran vacío debido a la "...falta absoluta de toda educación corporal de los niños...”. Sin el desarrollo físico, la educación se convertía en infanticida, porque se obligaba al niño a pasar tres y cuatro horas al día en un espacio cerrado donde cualquier movimiento era reprimido (Díaz Covarrubias, 1875:XXXI). Es hasta el $2^{\circ}$ Congreso de Instrucción Pública (1889-1890) que se muestra una verdadera preocupación por el desenvolvimiento físico del educando, como complemento del intelectual y el moral. Resultaba necesario educar al niño para que conociera sus órganos y sus funciones procurando "...el movimiento ordenado y gradual de los huesos y de los músculos para alcanzar la fuerza y la belleza de todo el organismo..." (Hernández, 1902: V-VII). Atender este programa impuso una serie de innovaciones en la escuela que iban desde la práctica de conferencias pedagógicas, fiestas y excursiones escolares, creación de escuelas especializadas y la publicación de libros de texto que orientaron la formación de los maestros y de los alumnos (La Escuela Mexicana, 1910: 341). Fue así que los libros se modernizaron: libros temáticos para cada una de las disciplinas escolares, graduados y ampliamente ilustrados. Para aprender a leer se siguieron diversos métodos y para ejercitar el aprendizaje, circularon textos que estimularon la lectura de corrido ${ }^{5}$, integrando todo el saber escolar en un solo volumen que incluía lecciones cortas escritas en prosa y verso, a través del uso de cartas, canciones y relatos breves.

Los libros mostraban la necesidad de una instrucción popular que preparara ventajosamente para comenzar un oficio o profesión porque sin, “...la instrucción y el trabajo nunca llegaréis a ser otra cosa que simples máquinas humanas y juguetes..." (Trigo, 1896:11). Un trabajo para el que había que preparar el cuerpo, por esto había que conocerlo bien. En general, las lecciones hacían hincapié en el conocimiento de los sentidos que ponían en comunicación con el entorno;

5. Esta reforma propició que en varios textos se aclarara que no se trataba de simples libros de lectura como en El Nuevo Lector Hispano-Americano, en el que "... hemos implementado las reformas del caso, sin alterar en lo más mínimo el sugestivo plan del autor, hasta hoy por nadie imitado, en la seguridad de que seguirán mereciendo la confianza del magisterio nacional..." (Gómez, 1918:10)

Pro-Posições, Campinas, v. 22, n. 3 (66), p. 35-49, set./dez. 2011 
Cuadro \# I.-Currículo escolar de la escuela primaria mexicana

\begin{tabular}{|l|l|}
\hline Moral práctica e instrucción cívica & \\
\hline Lengua nacional & Lectura y escritura \\
\hline Aritmética & \\
\hline Nociones de ciencias físicas y naturales & Lecciones de cosas \\
\hline Nociones prácticas de geometría & \\
\hline Nociones de geografía e historia patria & \\
\hline Dibujo & \\
\hline Contornos fáciles de objetos usuales y sencillos & \\
\hline Canto & \\
\hline Gimnasia y ejercicio militares & \\
\hline Labores manuales para las niñas & \\
\hline
\end{tabular}

Fuente: Canseco, 1904: 35'

con la vista se percibían los objetos y se sabía de su forma y color; con el oído, se conocían los sonidos; con el olfato los olores; con el gusto los sabores y con el tacto, se familiarizaba con la estructura de las cosas, sobre la que ponemos la mano u otras partes del cuerpo. Se aprendía también sobre la disposición de los órganos y su funcionamiento en procesos como la digestión y el reposo, pero también se alertaba al pequeño lector frente al consumo de bebidas que eran peligrosas para la salud: al alcohol y el pulque, cuyo consumo desmesurado provocaba el feo vicio de la embriaguez, que hacía perder el bienestar, la honra, la vergüenza, la estimación de los conciudadanos y el aprecio de la familia.

Una representación de los efectos que el alcohol producía en el cuerpo, se ubicaba, casi siempre, en el ejemplo del indígena o del campesino, que llevó a los ilustradores de los textos a imaginar el castigo que merecían los excesos y a mostrar la descomposición de órganos como el hígado, el corazón y el estómago en el cuerpo humano, como lo vemos en las siguientes imágenes que por primera vez mostraron la anormalidad de la infancia como resultado de estas desproporciones (Trigo, 1895:15-17; Trigo, 1896:115-118; Gómez, 1903:54, Tapia, 1913 :108111, 270-272):

Los espacios en el que los alumnos se desempeñaban giraban en torno a la escuela y al hogar, en cada uno de ellos se seguía una serie de reglas que regulaban el comportamiento infantil. Los salones de clases imponían un orden estricto a diferencia de lo que pasaba en la casa o en el patio de recreo. En las lecturas se describía a la escuela como el espacio en el que se reunían los niños, a partir de las

6. El desarrollo de todas las disciplinas escolares y sus libros puede consultarse en Galván y Martínez, 2010. 
ocho de la mañana y donde el maestro vigila la entrada. Una vez que la campana sonaba se atendía a una serie de órdenes de corte militar que obligaba a cada actor a ocupar su lugar:
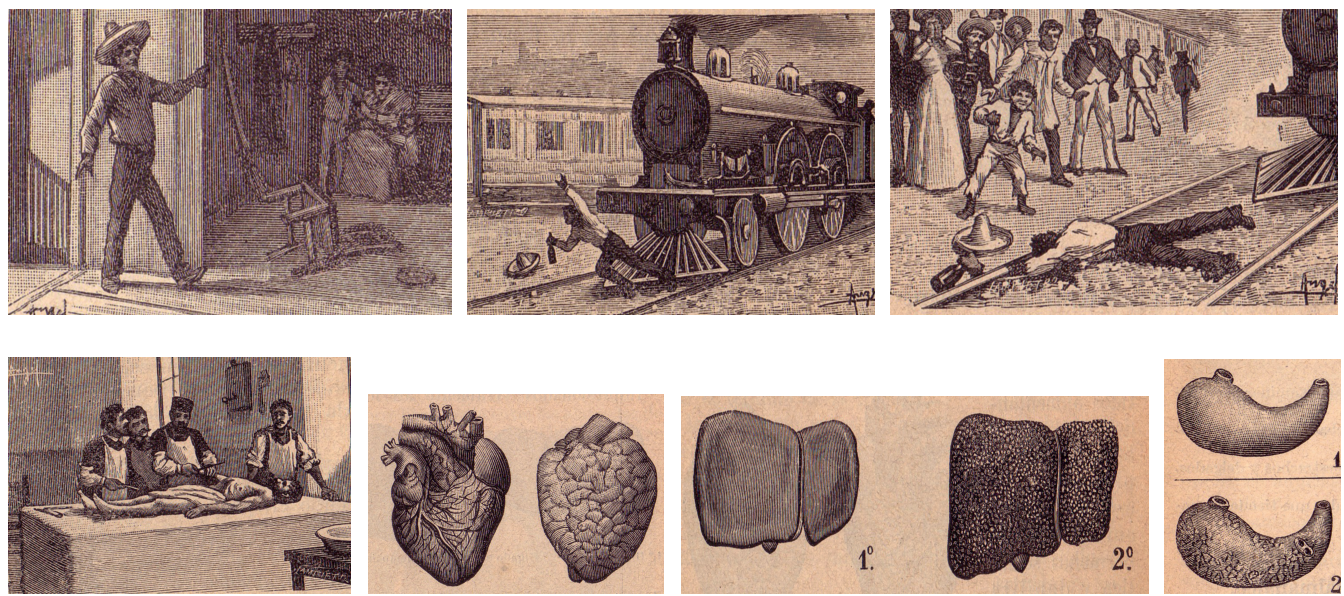

Figura \# I.- La autopsia de un alcohólico

Fuente: Tapia, 1913: 120

“¡A formarse $i$ Por el flanco derecho $\ldots$... Derecha $_{i j}$ De frente $\ldots$... ¡Marchen ¡...entramos al salón de clases... principia la clase... aprendemos a leer y escribir, dibujamos y cantamos y hacemos ejercicios de gimnasia. Todos los niños están muy quietos y prestan mucha atención. Todos obedecen a su maestro...." (Rebsamen, 1904:71-72)

La escuela era el espacio que se había modernizado dejando atrás la época en la que los maestros creían que la letra con sangre entra imponiendo a los niños azotes y castigos. Después de los congresos pedagógicos, se acordó que los espacios se transformarían y los salones de clase se convertirían en lugares de recreo y distracción donde, "...manejar la pluma...interpretar el libro, traducir la nota, leer en el árbol, en la flor, en el colibrí... (haría conocer) los mil secretos de la naturaleza...” (Gómez, 1903:146-147). En el salón de clases, el maestro ordenaba y vigilaba los cuerpos, a diferencia de lo que sucedía en el patio de recreo y en el campo, donde podían realizarse otras actividades como la media hora de recreación, entre clase y clase, así como la gimnasia y las excursiones escolares (Martínez, 2010).

Después de la clase, en el patio de recreo, los alumnos podían liberarse del mobiliario: "después del estudio j...vamos a jugar ;". Como se muestra en las imágenes, las alumnas podían saltar la cuerda y mecerse en los columpios; los alumnos por el contrario podían organizarse con el toro y años después jugar con 
los papalotes, los trompos, las canicas y las pelotas de varios tamaños. Un espacio donde se permitía jugar, correr, saltar y gritar, siempre moderadamente para no fatigarse porque de lo contrario se disminuiría el ánimo para volver a su trabajo, que era el estudio. Las niñas debían procurar que los juegos no se convirtieran en retozos porque podrían lastimarse o buscar disgustarse con alguna compañera, era pues importante, "... contener lo brusco de sus modales y evitar los juegos pesados y peligrosos que no eran propios". La actividad y el juego al aire libre hacía que las mejillas se colorearan y que el cuerpo recobrara la salud (Rebsamen, 1899:61; Torres Quintero, 1911:4,18; Rosales, 1908:141-142). Durante los años cuarenta, los juguetes pasaron a segundo plano y las lecciones señalaron las ventajas de disfrutar de la naturaleza; en las lecciones se muestra el gozo por correr en el campo, brincar debajo de los árboles, rodar en la hierba, bañarse en el arroyo y, las niñas, preparar un ramo con flores silvestres (SEP, 1938:89-90). Será hasta la década de los 40, cuando la legislación no exima a los niños enfermos de ausentarse de la escuela y se muestre el rechazo hacia los defectos físicos. Hay lecciones que asocian a un ser inofensivo, jorobado, cojo y por añadidura tuerto que no podía detener la burla y el maltrato de sus compañeros con su excelente corazón (Delgadillo, 1940: 70).

Los libros escolares mostraban que en el hogar se practicaban una serie de rituales que protegían el cuerpo de las impurezas: con ayuda del agua fresca y limpia, y no del perfume y otras cosas que alteran, se llevaba a cabo el lavado de manos, brazos y cara así como de boca, ojos y oídos que transformaban a un niño en limpio, agradable y simpático, que al verle, daban ganas de besarlo (Torres Quintero, 1911:4). En el caso contrario, se rehuía de las niñas coléricas, enojonas y hurañas, cuyos atributos las hacían antipáticas y ridículas. El desaseo hacía que las niñas, por más bonitas que fueran, parecieran feas, despertando mas asco que simpatía (Rosales, 1908:38-39; 122-123)
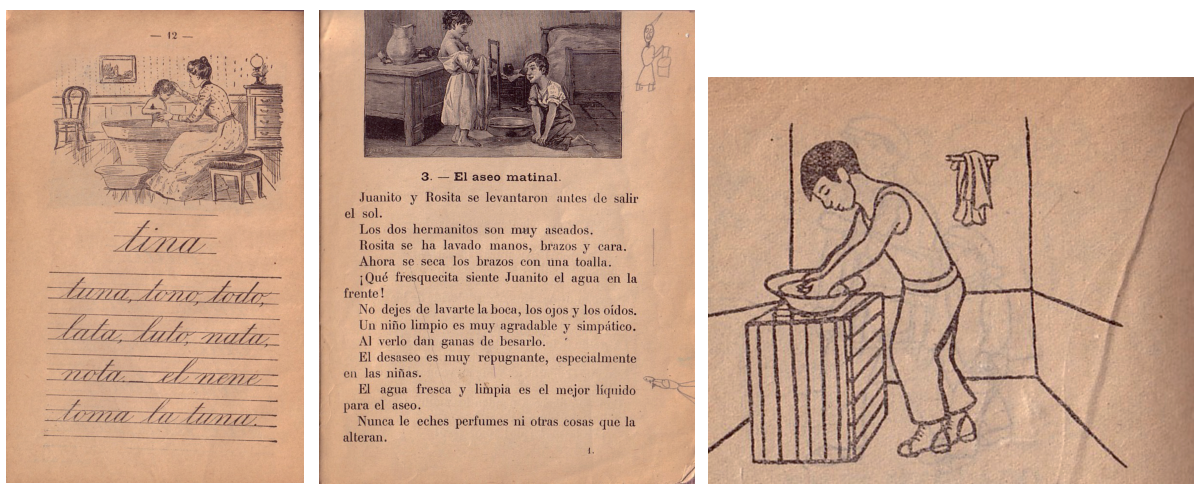

Figura\#2.-La higiene corporal Fuente: Rebsamen, 1904: I2; Torres Quintero, 191 I; 34 ; SEP, I 938 :76 
Los libros para niñas mostraron que una buena alimentación, ejercicio y un respeto por los horarios de descanso hacían que las niñas tuvieran hermosa mirada, llena de vida y labios encendidos. Para tener una dentadura blanca y sana hacía falta limpiar a diario con un cepillo suave y polvos finos para no rayar el esmalte (Rosales, 1908: 34-35)

Hubo textos que fueron escritos especialmente para las niñas, en los que se subrayaba la importancia del aprendizaje de la higiene no sólo personal sino de los espacios en los que se desempeñaban. Además del escolar, el hogar jugó un papel importante para realizarse como pequeñas madres, enfermeras e hijas de familia. Para cumplir con estos roles era necesario contar con salud física y mental para, “...sacudir las sábanas y colchones de la cama...lavarse y peinarse... saludar a papá...y después... jal campo; (Rodríguez 1906:16).

El discurso en estos libros estaba dirigido a cumplir satisfactoriamente el futuro que les estaba destinado: convertirse primero en amas de casa y posteriormente en ciudadanas. Por esto había lecciones que preparaban para el conocimiento del corte y la confección de prendas así como el bordado y el aseo de una casa. Para esta última actividad había que vestir el cuerpo de una manera determinada para poseer las cualidades de una mujer hacendosa y limpia: subir las mangas hasta el codo, usar un mandil lavable y portar en la cabeza un lienzo atado por detrás para cubrirse del polvo. Una vez que el cuerpo se cubría con un vestuario determinado, podían iniciarse las labores de trapeado de pisos y sacudido de muebles. Si no se realizaban estas labores con atención, el costo era demasiado alto pues los gérmenes de enfermedades como el tifo, la tuberculosis podían entrar a través de la nariz y la boca (Rodríguez 1906:45).

A pesar del peligro que representaba el contagio de algunas enfermedades, con estas actividades las niñas podían salir de la rutina del salón de clases para adoptar otros movimientos: arrodillarse para limpiar los pisos, mantenerse en pie para el aseo de las ventanas, mover el brazo de un lado a otro para la limpieza de paredes, inclinarse para sacudir por debajo de las camas, batir y estrujar el lienzo (Rodríguez 1906:144). Para hacer estas labores era necesaria la disciplina y la concentración que servían en el aprendizaje del hilado y el bordado. Los preceptos higiénicos señalaban que las clases debían ser de no más de cuarenta minutos, alternando ejercicios mecánicos con intelectuales con unos minutos de recreo, lo que no exentaba la fatiga mental. Por esto el remedio, al llegar a casa, era cambiar el uniforme por

el traje de casa, cambiar tus botitas nuevas y brillantes por tu calzado de tosco cuero y gruesa suela...e ir al jardín... aire puro, fresco, libre, bien oliente, a diferencia de ..la clase..(donde) podrás moverte libremente, irás de aquí para allá, te agitarás removiendo la tierra, con tu pequeña coa, tu imaginación descansará de los problemas geométricos y

Pro-Posições, Campinas, v. 22, n. 3 (66), p. 35-49, set./dez. 2011 
de los geográficos y tu vista podrá recrearse con las rosas, las amapolas...aquel tan grato ejercicio ha vuelto a su ánimo la alegría y a su cuerpo la energía y el vigor que por el trabajo habían disminuido..."(Rodríguez 1906:99)

Los textos mostraban que una buena educación en el hogar tenía que ver con la manera de comer y la alimentación: usar los cubiertos, inclinar la cabeza para tomar cada bocado, no hablar con la boca llena ni hacer ruido al beber líquidos, no mecerse en la silla ni manchar los manteles, no disputarse el pan con los hermanos ni levantarse de la mesa antes que sus padres, al finalizar lavar la boca y las manos (Hidalgo Monroy 1925: 109). Era necesario alimentar el cuerpo lo suficiente para que hiciera su trabajo pero sin hartarse para evitar indigestiones y sobre todo evitar ciertos alimentos de consumo popular como el nopal, considerado una planta humilde y vulgar, cuyas hojas carnosas y sembradas de espinas, cuando estaban tiernas, servían solamente de alimento a los indígenas o en algún plato de vigilia (Rosales, 1908:49-50). Una representación que se invierte, en los libros de los años 30 pues, durante el período de la educación socialista, el menú familiar valora el alimento del campo que nutre al cuerpo con tortillas calientes, frijoles y una buena salsa. En las excursiones escolares, por ejemplo, los niños olvidan las naranjas que recolectan de los árboles y comen bolillos dorados de frijoles y huevo puestos en su tenate. En casi todas las imágenes que acompañan a las lecciones se recuperan las virtudes del campo sobre la salud; se observa a la familia sentaba a la sombra del árbol junto al río, comiendo despacio, saboreando la comida, no apartando nunca los ojos, de los grandes surcos (SEP, 1938: 56 y 87-88)

En general las lecciones abogaban por la necesidad de combatir la ignorancia del indígena enseñándole a respetar las leyes de la naturaleza para evitar las enfermedades del cuerpo: después de una suculenta comida estaba prohibido tomar un baño de agua fría porque era el momento en el que la digestión estaba en pleno vigor, el efecto sería la muerte; las enfermedades de los ojos se producían cuando se abusaba de la vista cosiendo o leyendo en sitios con escasa luz o donde hubiera una lámpara de petróleo, la luz del sol sobre el libro, o el paso hacia un lugar frío; si llegaba la enfermedad se aconsejaba el lavado con agua fresca y unas gotas de limón.

Ante la enfermedad del cuerpo se mostraban diferentes posiciones: si se trataba de una familia que vivía en la ciudad donde los niños asistían a la escuela, la respuesta se aprendía en las lecciones de los libros: una herida que sangraba en la cabeza, se mitigaba lavando la zona y aplicando árnica con un algodón empapado. Pero si la respuesta llegaba de la población indígena, ignorante y supersticiosa, la enfermedad se convertía en un terreno de disputa entre el bien y el mal donde el mal de ojo y la muerte se medían con el cantar de un búho (Rodríguez 1912: 140-142). En el centro se encontraban los consejos del médico quien en una lección señalaba los 
beneficios de las vacunas, el ejercicio y la buena alimentación para combatir los efectos del sarampión y la viruela; (Rodríguez, 1906:186-188)

El cuerpo era el agente principal de la vida física del hombre, para conservarlo había que conocer sus funciones y las consecuencias de la ignorancia sobre la salud, que bien podían dejar al individuo inválido de por vida. El cuerpo era considerado una pequeña pero muy valiosa parte de la naturaleza, por esto no era posible dejar de apreciar su importancia y sobre todo sus beneficios al conocerlo (Trigo, $1895: 126$ )

Siendo el cuerpo humano, una maquina maravillosa, era necesario conocer a detalle cada uno de los órganos para mantenerlo sano: los aparatos digestivo, respiratorio, circulatorio y el sistema nervioso. Una máquina compleja y sorprendente que protegía a otras máquinas complementarias: la inteligencia, la razón, el espíritu y el alma. Para su buen funcionamiento había que mantener un equilibrio entre la fatiga y el reposo para recuperar la energía gastada: las actividades que se realizaban en una oficina debían combinarse con los trabajos de jardinería; el trabajo de la fábrica con el paseo en el campo para respirar el aire puro. La lección concluía con una sabia recomendación: "como se guarda en un fino estuche de terciopelo y seda, el brillante... que vale una fortuna, guarda tú, con todos tus cuidados el diamante más costoso que posee: la salud“ (Huerta, 1945: 229-240).

Algunas imágenes mostraban las características del niño como un adulto en miniatura, un ser débil y limitado que asociado a la limpieza y el orden lo convertía en un buen niño (Parmegiani, 1997:57). Idea que convivía con otra en la que se invitaba a los niños a conocerse bien describiendo su aspecto físico y moral redactando su biografía, o la historia de su vida, en la que se invitaba al niño a saber quién era él, saber sobre sus amigos, su padres, su escuela, el lugar en el que vivía, sus ocupaciones (Gómez , 1903: 29)

Conociendo su cuerpo, el niño se encargaría de protegerlo. El calor le hacía reflexionar sobre el exterior y la necesidad de las ropas de abrigo para impedir que la temperatura interior se escapara. Una diferenciación entre el vestido mexicano, de la ciudad y del campo, mostró hacia los años veintes que la vestimenta que cubría el cuerpo en la ciudad consistía en el saco, el chaleco, el pantalón de casimir o de dril, con sombrero y calzado fino; mientras que en el campo, los trajes eran más variados: en el clima frío, la manta, los cotones de lana para el trabajo y el capizallo o capote de palma, para la lluvia; en el clima caliente, la camisa y el calzoncillo de manta, el huarache y el sombrero de palma. Solo en los ranchos se vestía el traje de charro y la vestimenta de lujo se reservaba para el domingo (Rosales, 1908: 89-90; Hidalgo Monroy, 1925: 88)

En cuanto a la formación de los ciudadanos, la ley reconocía que se adquiría ese estatus con la mayoría de edad, 21 años si se era soltero o 18 si era casado. Visto que los lectores contaban con un promedio de 8 a 12 años de edad, faltaba mucho 
tiempo para convertirse en un hombre libre, honrado, con un modo honesto de vivir, con un oficio, una profesión o cualquier trabajo que les permita vivir honradamente; mientras esto ocurría había que ocupar el tiempo con la pelota mientras las niñas se entregaban a otros juegos propios de su sexo. Finalmente para ser heroínas y prestar servicios importantes a la nación, bastaba con proponerse ser buenas y cumplir fielmente sus deberes (Rodríguez 1906:119; Rodríguez, 1912: 27). Una imagen que se mantuvo hasta los años cuarenta pues las niñas desempeñaban un doble trabajo; antes de salir a la escuela, se encargaban de preparar el desayuno, barrer los pisos, sacudir las paredes o arreglar las camas, a su regreso, al hogar feliz, "descansaban leyendo un libro de cuentos o algo instructivo" (De la Brena, 1906: 87; Delgadillo, 1940:25).

Es curioso observar que en algunos textos para niñas, las lecciones de historia y moral, privilegiaron la presentación de biografías femeninas, lo que resulta interesante pero sorprendente a la vez, pues el rol que jugaron estas mujeres durante el movimiento de Independencia contradice la idea de obediencia y disciplina que quería imponerse a lo largo de las lecturas ${ }^{7}$. Se habla de Manuela Taboada, esposa heroica de Abasolo, compañero de Hidalgo y Allende ${ }^{8}$, de Josefa Ortiz de Domínguez $^{9}$, de Leona Vicario ${ }^{10}$ y de Sor Juana Inés de la Cruz ${ }^{11}$. Una imagen desafiante, llena de entusiasmo, viveza, patriotismo, pero femenina al fin pues, como se señala en una lección:

"Los hombres... demostramos nuestro cariño por la patria, y la honramos derramando valerosamente por ella, nuestra sangre en las batallas, o procurando distinguirnos en el país como hombres instruidos, laboriosos y honrados; las niñas inocentes y delicadas la honran como Rafaelita, siendo alumnas distinguidas en la escuela y en el hogar" (Rosales, 1908: 134.136)

7. "Al estudiar la Historia, encontraréis hermosos ejemplos de madres que se han sacrificado por sus hijos, de esposas que han arrostrado mil peligros por salvar a sus maridos, de hijas que nada temieron y desafiaron todo por alcanzar la dicha de sus padres. iBenditas heroínasi consagradles un recuerdo, un pensamiento y una lagrima..." (Rodríguez 1906:164)

8. "E Chihuahua....su marido es juzgado. En sus declaraciones, acumuló sobre sus compañeros cuantas acusaciones pudo; y dio muestra de una debilidad que contrastó notablemente con el heroísmo de su esposa. Debido a las delaciones que hizo... no fue condenado a muerte, sino a prisión perpetua en España" (Rodríguez 1906: 169-170)

9. "Su conducta nos demuestra el sin igual patriotismo que animaba su corazón y la nobleza de sentimientos de que dotó Dios su alma para nuestro bien. Pronunciad con respeto su nombre y recordadla con reconocimiento..." (Rodríguez 1906: I 07- I I I)

10. "Haciendo lo propio para romper eslabón por eslabón, las cadenas que un pueblo soportara por espacio de tres siglos" (Rodríguez 1906:257)

I I. "Sirva la historia de Sor Juana... para demostrar que también la mujer puede dar gloria a la patria, y que México es cuna de mujeres inteligentes, virtuosas e ilustradas " (Rosales, : I68) 
Los héroes, en realidad, siempre fueron del género masculino, como en los libros de historia, donde se sacrificaban por la Patria (Rodríguez, 1912: 22-23), por esto resulta interesante observar que un solo manual donde se ejercitaba la lectura de corrido, advierte sobre la idea de otro héroe infantil; un héroe que no tiene que luchar en grandes batallas sino en lo cotidiano participando como un ciudadano responsable de su entorno. En la lección que narra la actitud de un niño frente al incendio en una casa, las imágenes acompañan al texto: por primera vez se ve al héroe en acción y convierte a la lectura en un texto placentero aunque no original pues seguramente el ilustrador de El viaje de dos niños huérfanos de Lucio Tapia, se inspiró del texto francés de Jean Perrot, publicado a finales del siglo XIX por la editorial Nathan. La secuencia que narra un incendio lleva, al protagonista de la aventura, a convertirse en el héroe que salva a su amigo quien se encuentra en medio de las llamas. El objetivo de la imagen, a semejanza de lo que ilustra Fernand Fau, es mostrar el movimiento justo de los personajes y los objetos a través de formas simples para hacerlos reconocibles porque los niños, según su concepción, estaban habituados a “...leer la imagen, a analizarla, a distinguir sus diversas partes ${ }^{12}$.
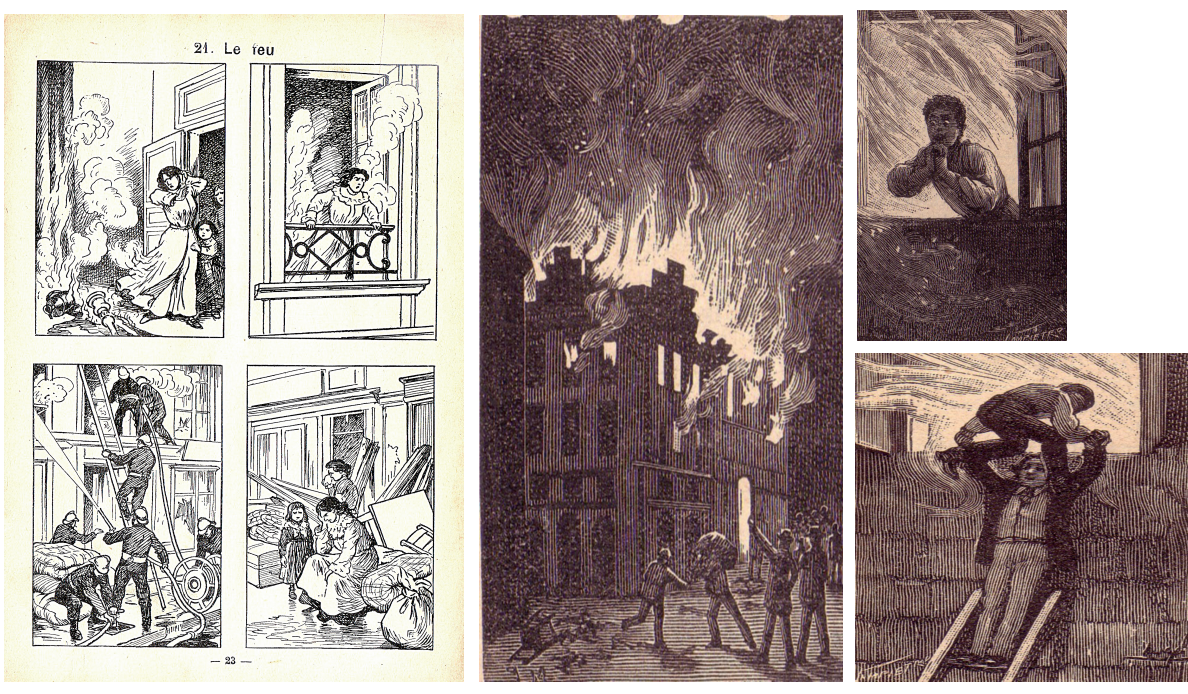

Figura \#3 .- El fuego

Fuente: Perrot y Fau, 1911:23; Tapia, 1913: 218-220

12. "... habitués à lire l'image, a l'analyser, a en distinguer les diverses parties, les enfants aborderont ce nouveau livre... et pourront se livrer a un travail fructueux tant au point de vue de l'acquisition des idées que de l'augmentation du vocabulaire...le dessinateur s'est appliquée a donner aux personnages le mouvement juste, et aux objets les formes les plus simples qui les rendent facilement reconnaissables. Nous croyons fermement qu'il a réussi... » (Perrot y Fau, s/f :2)

Pro-Posições, Campinas, v. 22, n. 3 (66), p. 35-49, set./dez. 2011 
Una estrategia que rompía con la rigidez de otros libros que se centraban únicamente en el texto, como en la siguiente narración que cuenta como se rompía el orden durante la época decembrina cuando los niños rompían piñatas precipitándose sobre las frutas y las golosinas, “....aranándose las manos mutuamente y arrastrándose en el suelo...”, actividades que se compartían y que provocaban una actitud propia de su edad: las risas y los alborotos, que hacían reír también a los padres "a carcajadas" (Torres Quintero, 1911:45)

\section{Referências bibliográficas}

CANSECO, M. Guía del profesor. 2. ed., México: Librería de la Vda. De C. Bouret, 1904. Obra escrita en vista de los autores más notables por...y aprobada por el Consejo Superior de Instrucción. Contiene todas las reglas necesarias para la enseñanza moderna.

DE LA BRENA, L. El niño mexicano. Método moderno de lectura dividido en cuatro partes progresivas. Libro segundo. México: Herrero Hermanos Sucesores, 1906.

DELGADILLO, D.jAdelante; . Libro Tercero. México: Herrero Hermanos Sucesores, 1940.

DÍAZ COVARRUBIAS, J. La instrucción pública en México. México: Porrúa, 1875. Edición facsimilar de la publicada en México.

GALVÁN LAFARGA, L. E.; MARTÍNEZ MOCTEZUMA, L. Las disciplinas escolares y sus libros. México: CIESAS, UAEM; Juan Pablos Editor, 2010.

GÓMEZ, R. El lector hispano-americano. Libro segundo de lectura. México: Herrero Hermanos Editores, 1903.

GÓMEZ, R. El nuevo lector hispano-americano. Libro tercero de lectura. México: Herrero Hermanos Editores, 1918.

HERNÁNDEZ, J. S. Álbum pedagógico y escolar. Conferencias científicas dadas en la Escuela Normal de México, artículos pedagógicos, discursos, pensamientos, etc. México: Oficina Tipográfica de la Secretaría de Fomento, 1896.

HIDALGO MONROY, L. jLevántate; . Libro primero de lectura para uso de los alumnos del segundo año elemental. México: Herrero Hermanos Sucesores, 1925.

HUERTA, D. Mi patria. Libro quinto de lectura. Mexico: El Material Didáctico, 1945.

LA ESCUELA mexicana. Órgano de la Dirección General de Educación Primaria del Distrito Federal. México, 1910.

MARCOIN, F. El placer de leer: entre lo anticuado y lo novedoso. In: PARMEGIANI, C-A. (Dir.). Lecturas, libros y bibliotecas para niños. España: Fundación German Sanchez Ruiperez, 1997.

MARTÍNEZ MARTÍN, J. A. (Ed.). Historia de la lectura en Ayer. Revista de Historia Contemporánea, España, n. 58, 2005. (2) 
MARTÍNEZ MOCTEZUMA, L. Historia de la educación física en México. In: SCHARAGRODSKY, Pablo Ariel (Comp.). La invención del "homo gymnasticus". Fragmentos históricos sobre la educación de los cuerpos en movimiento en Occidente. Argentina: Prometeo, 2011.

OSSENBACH, G.; SOMOZA, M. (Ed.). Los manuales escolares como fuente para la historia de la educación en América Latina. España: UNED Ediciones, 2001.

PARMEGIANI, C-A. La epifanía de los libros de imágenes. In: PARMEGIANI, CA. (Dir.). Lecturas, libros y bibliotecas para niños. España: Fundación German Sanchez Ruiperez, 1997.

PERROT, J.; FAU, F. 54 Leçons de choses en images sans paroles a raconter par les petits. Deuxième livre d'initiation et d'élocution. Paris: Librairie classique Fernand Nathan, 1911.

PORTER, R. Historia del cuerpo. In: BURKE, P. (Ed.). Formas de hacer historia. España: Alianza Universidad, 1993.

REBSAMEN, E. C. Método de escritura-lectura o sea enseñanza de lectura por medio de la escritura con aplicaciones del fonetismo y la marcha analitica-sintética (palabras normales). México: Antigua Librería de Ch.Bouret, 1904.

RODRÍGUEZ, D. C. La perla de la casa. Libro tercero de lectura para uso de las niñas que cursan cuarto año de instrucción primaria elemental. México: Librería de la Vda. de Bouret, 1906.

RODRÍGUEZ-NAVAS, M. Dr. Rafaelita. Historia de una niña hacendosa. Libro cuarto de lectura para uso de las niñas. Por una profesora Normal revisado y corregido por el... México: Herrero Hermanos Sucesores, 1912.

ROSALES, M. M. Rafaelita. Libro primero de lectura para uso de las alumnas del segundo año elemental. México: Herrero Hermanos Sucesores, 1908.

RUIZ SOMAVILLA, M. J. El cuerpo limpio. Análisis de las prácticas higiénicas en la España del mundo moderno. España: Universidad de Málaga, 1993.

MÉXICO. Secretaría de Educación Pública. Escuelas urbanas. 1er año. Lectura oral. México: Comisión Editora Popular de la SEP, 1938. Serie SEP.

TAPIA, L. Viaje a través de México por dos niños huérfanos. México: Herrero Hermanos Sucesores, 1913.

TORRES QUINTERO, G. El lector infantil mexicano. México: Librería de la Vda. de C. Bouret, 1911.

TRIGO, J. M. El niño ilustrado. Libro cuarto de lectura o preparación al estudio de las ciencias. EUA: Spanish-American educational, 1895.

TRIGO, J. M. El niño ilustrado. La ciencia al alcance de los niños. Libro tercero de lectura. Un paseo científico en el campo. EUA: Spanish-American educational, 1896.

URUCHURTU, A. E.; ALCONEDO, E. RIE. Método de lectura y escritura para primer año. México: Sociedad de Edición y Librería Franco Americana, 1928.

Pro-Posiçôes, Campinas, v. 22, n. 3 (66), p. 35-49, set./dez. 2011 
VIGARELLO, G. Corregir el cuerpo. Historia de un poder pedagógico. Argentina: Ediciones Nueva Visión, 2001.

Recebido em 28 de março de 2011 e aprovado em 27 de maio de 2011. 
